\title{
La travesti permitida y la narcotravesti: imágenes morales en tensión*
}

María Soledad Cutuli**

\section{Resumen}

En este artículo nos preguntamos por el llamado "giro conservador" y su impacto en la situación de las travestis en Argentina. Analizamos la construcción de dos imágenes morales controvertidas: la travesti permitida y la narcotravesti. En el marco de las políticas de empleo que entre 2003 y 2015 movilizaron la idea de trabajo digno, la primera imagen representa a aquellas que demandaron y conquistaron una inserción laboral diferente de la prostitución desde un paradigma abolicionista. En contraposición, la narcotravesti es una figura cristalizada recientemente en un polémico fallo del Tribunal Oral en lo Criminal I de La Plata, que condenó a una peruana a prisión por venta de droga y cuya pena fue agravada por su condición de extranjera. Dicha figura fue replicada en relatos policiales y periodísticos, dando cuenta del recrudecimiento de la represión policial en las zonas rojas y de la creciente estigmatización de las migrantes. El despliegue de estas dos imágenes nos permite explorar, por un lado, las intersecciones políticas y morales que trazan los límites de lo posible y lo aceptable para las travestis, y por otro, la configuración de vulnerabilidades diferenciales en un contexto de retroceso y pauperización de sus condiciones de vida.

Palabras clave: Travestis, Moralidades, Política, Antropología.

\footnotetext{
Recebido para publicação em 15 de dezembro de 2016, aceito em 8 de fevereiro de 2017.

** Facultad de Filosofía y Letras, Instituto de Ciencias Antropológicas, Universidad de Buenos Aires, Buenos Aires, Argentina. soledadcutuli@gmail.com 
The Permitted Travesti and The Narcotravesti: Moral Images in Tension

\begin{abstract}
This paper inquires on the "conservative twist" and it impact on travestis' lives in Argentina. In this regard, two moral images are analysed: the permitted travesti and the narcotravesti. The former represents those who struggled for a dignified work within an abolitionist paradigm. The latter, on the contrary, was recently crystalized in a sentence that sent a Peruvian travesti to prison for drug dealing, considering the fact of her being foreigner as an aggravating circumstance. The narcotravesti image was widely spread by the media, informing the rise in police repression and the stigmatization of migrant people. The analysis of these two images contribute to explore, on the one hand, the moral and political intersections that constrain the limits of the possible and acceptable for travestis, and, on the other, the configuration of specific vulnerabilities within a repressive context.
\end{abstract}

Keywords: Transgender People, Moralities, Politics, Anthropology. 
En el año 2016 varios de los países de nuestra región se encontraban procesando la derrota de gobiernos progresistas que, aún con contradicciones y fisuras, venían de mejorar notablemente las condiciones de vida de sectores populares previamente devastados por el neoliberalismo. En Argentina, el mundo social de la diversidad sexual en particular resultó adicionalmente golpeado por la pérdida de Lohana Berkins y Diana Sacayán, principales referentes travestis, en febrero de 2016 y octubre de 2015 respectivamente.

Desde comienzos de la década de 1990 se formaron agrupaciones de travestis para denunciar la violencia policial y resistir, junto a otros sectores estigmatizados, los códigos contravencionales que criminalizaban la expresión de sus identidades en el espacio público. En este proceso fueron articulando sus demandas con organismos de Derechos Humanos, grupos feministas y de la diversidad sexual, sectores progresistas y de izquierda - entre otros - generando una acumulación y visibilidad de crecimiento exponencial. Más de veinticinco años después del surgimiento de la primera agrupación, las asociaciones se multiplicaron y avanzaron notablemente en el reclamo por sus derechos. Varias de ellas presentaron diversas propuestas para una Ley de Identidad de Género, consiguiendo en mayo de 2012 la formulación de un proyecto unificado y su sanción como Ley n ${ }^{\circ}$ 26.743. Esta nueva legislación estableció, por un lado, la posibilidad de rectificación registral del sexo y el cambio de nombre de pila e imagen, cuando no coincidieran con la identidad de género autopercibida por la persona, sin el requisito de intervención judicial, y sin necesidad de acreditar una intervención quirúrgica por reasignación genital total o parcial, ni terapias hormonales u otro tratamiento psicológico o médico. Por otro lado, se incorporó como un derecho el acceso a intervenciones quirúrgicas totales y parciales, y/o tratamientos integrales hormonales para adecuar el cuerpo - incluida la genitalidad - a la identidad de género autopercibida, con la sola firma de un consentimiento informado, sin necesidad de requerir autorización judicial o administrativa. Con la finalidad de 
"garantizar el goce - la salud integral", dicha Ley incorporó las mencionadas prestaciones de salud al Plan Médico Obligatorio.

La sanción de esta ley fue mundialmente considerada a la vanguardia de los Derechos Humanos. La lucha por la derogación de los Edictos Policiales parecía haber quedado en un pasado remoto: mientras se trataba la ley, los/as legisladores/as pedían disculpas en nombre del Estado por las violencias perpetradas y retomaban las consignas, argumentos, $e$ incluso datos cuantitativos de las organizaciones para expedirse a favor de la nueva norma, aprobada casi por unanimidad. Junto con la ley de Identidad de Género, una serie de otros avances en materia de derechos sexuales protagonizó el período 2003-2015: las leyes de Salud Sexual y Procreación Responsable ( $\mathrm{n}^{\circ}$ 25673), Educación Sexual Integral $\left(\mathrm{n}^{\circ}\right.$ 26150), Protección Integral para Prevenir, Sancionar y Erradicar la Violencia hacia las Mujeres ( $\left.n^{\circ} 26484\right)$, la modificación de la ley de Matrimonio Civil para incluir las uniones entre personas del mismo sexo (conocida como ley de Matrimonio Igualitario), sólo por nombrar los más destacados. Si bien implementados con dificultades durante la gestión anterior $-\mathrm{y}$ con la ley de Interrupción Voluntaria del Embarazo aún pendiente- los mencionados derechos adquiridos se vieron seriamente amenazados con la asunción del nuevo gobierno, a través del desmantelamiento de áreas estratégicas, el recorte presupuestario y el despido de las/os trabajadores que las sostenían.

Este artículo propone reflexionar sobre este proceso vivo que podría llamarse "retroceso" o "giro conservador" - a través de la situación de las travestis de Buenos Aires y La Plata. Para ello desarrollo y analizo la construcción de dos imágenes morales controvertidas: la travesti permitida y la narcotravesti. En el marco de las políticas de empleo que entre 2003 y 2015 movilizaron la idea de trabajo digno, la primera imagen representa a aquellas que demandaron y conquistaron una inserción laboral diferente de la prostitución desde un paradigma abolicionista. ${ }^{1}$ En

1 En la Argentina a fines del siglo XIX comenzó a discutirse la reglamentación de la prostitución. Entre 1875 y 1935 se estableció un reglamento para disponer 
contraposición, la narcotravesti es una figura cristalizada recientemente en un polémico fallo del Tribunal Oral en lo Criminal I de La Plata, que condenó a una travesti de nacionalidad peruana a prisión por venta de droga y cuya pena fue agravada por su condición de extranjera. Dicha figura fue replicada en relatos policiales y periodísticos, dando cuenta del recrudecimiento de la represión policial en las zonas rojas y de la creciente estigmatización de las migrantes. Argumento entonces que el despliegue de estas dos imágenes permite explorar, por un lado, las intersecciones políticas y morales que trazan los límites de lo posible y lo aceptable para las travestis, y por otro, la configuración de vulnerabilidades diferenciales en un contexto de pauperización de sus condiciones de vida.

Los datos aquí desplegados surgen de dos etapas de trabajo de campo: una realizada entre 2008 y 2013 para mi tesis doctoral ${ }^{2}$, y otra actualmente en curso, iniciada a fines de 2015. Si los cinco años de registros en los que se apoyó la primera investigación documentan en gran medida conquistas en términos de derechos y de oportunidades de vida para las travestis; el nuevo período

sobre las "casas de prostitución", sobre la base de la necesidad de controlar a la higiene y salud de las mujeres. En 1936, en el marco de la Ley 12331 de profilaxis venérea, el anterior reglamento fue derogado y Argentina pasó a suscribir el abolicionismo. Bajo este nuevo paradigma los prostíbulos no cerraron, sino que pasaron a funcionar clandestinamente (Chejter, 2009). Las organizaciones feministas que sostienen actualmente el abolicionismo en Argentina se oponen a considerar la prostitución como un trabajo, entendiéndola como una situación generada por la siniestra articulación del capitalismo y el patriarcado. Entienden que -más allá de las condiciones en que sea ejercida- la prostitución es degradante y debe ser erradicada; desalentando para ello su reconocimiento jurídico. Aunque no medie un proxeneta, desde este paradigma se considera que la prostitución nunca constituye una elección libremente consentida, sino parte de la violencia de género patriarcal que atenta contra la dignidad de las mujeres. Estos principios fueron retomados de elaboraciones desarrolladas por teóricas abolicionistas, que consideraron a toda forma de prostitución como esclavitud sexual (MacKinnon, 1989; Pateman, 1995).

2 "Entre el escándalo y el trabajo digno. Etnografía de la trama social del activismo travesti en Buenos Aires". Tesis doctoral en Antropología, Universidad de Buenos Aires. 
presenta la complejidad de relevar las iniciativas del activismo para sobrellevar la ausencia de sus principales referentes mientras se agudizan los embates represivos.

\section{Las disputas por el espacio público}

Las primeras travestis que empezaron a organizarse a principios de la década de 1990 compartían experiencias similares de persecución, maltrato y violencia policial. Los Edictos Policiales vigentes en ese momento, tanto en la ciudad de Buenos Aires como en las provincias, eran disposiciones según las cuales las diferentes fuerzas de seguridad podían reprimir -sin intervención judicial- los actos no previstos en el Código Penal de la Nación. Los Edictos regulaban una serie de conductas no consideradas delictivas, pero sí "amenazantes de la convivencia social" y castigadas con penas como multas o arrestos de hasta treinta días (Pita, 2004). ${ }^{3}$ En 1985, el Congreso sancionó la Ley 23.184, creando siete nuevas figuras contravencionales (Art 21-27), y dando a la Policía Federal competencia para su juzgamiento (Art 30); ratificando, por ende, el poder de la policía de aplicar los Edictos (Gentilli, 1995).

Entre los Edictos Policiales, los artículos $2^{\circ} \mathrm{F}$ y $2^{\circ} \mathrm{H}$ afectaban directamente a las travestis. El primero reprimía con multas en dinero, o entre seis y veintiún días de arresto, a quienes "se

${ }^{3}$ Luego en 1932 - bajo la presidencia del presidente de facto José Félix Uriburu - se agregaron nuevos Edictos: en tanto conjunto inorgánico de numerosos reglamentos, decretos, decretos-leyes y leyes, los Edictos policiales fueron sucesivamente reformulados, re-escritos y ratificados por gobiernos militares y democráticos. En 1944 el gobierno de facto del Gral. Farrell estableció el primer Estatuto de la Policía Federal, autorizando a la policía a emitir y aplicar edictos para reprimir actos no previstos por las leyes, y dictar las reglas de procedimiento para su aplicación. En 1947, bajo el gobierno constitucional del Gral. Perón, el Congreso Nacional ratificó varios de los decretos del anterior gobierno, dándole fuerza de ley a los Edictos. En 1956, el presidente dictatorial Aramburu ratificó nuevamente todos los Edictos existentes hasta ese momento; siendo otra vez legitimados por el Congreso Nacional en 1958, durante el gobierno democrático de Frondizi. 
exhibieren en la vía pública o en lugares públicos vestidos o disfrazados con ropas del sexo contrario"; mientras que el segundo penaba a "las personas de uno $\mathrm{u}$ otro sexo que públicamente incitaren o se ofrecieren al acto carnal" (Gentilli, 1995; Berkins; Fernández, 2005). Ambas contravenciones se resumían en la idea de escándalo en la vía pública, una categoría recurrente en los Edictos que resultó un argumento central de las distintas fuerzas de seguridad para definir, reprimir y encarcelar a estas personas, estuvieran o no ejerciendo la prostitución en la vía pública (Cutuli, 2012).

El debate por la derogación de estos códigos comenzó a plantearse con el establecimiento de la autonomía de la Ciudad de Buenos Aires en 1997. En ese momento las travestis multiplicaron sus apariciones públicas, exponiendo sus condiciones de vida, $y$ especialmente el maltrato policial. Protestaron frente a la Legislatura porteña contra la prohibición de circular por la calle con ropas del sexo contrario; algunas se encadenaron al edificio de Tribunales, e incluso fueron recibidas por la Jefatura de Gobierno de la Ciudad de Buenos Aires (Fernández, 2004). Se definieron a sí mismas como "el colectivo al que aún no le ha llegado la democracia", argumentando que las disposiciones que regulaban el uso del espacio público criminalizaban la identidad travesti dado que era en las calles donde trabajaban quienes se encontraban en situación de prostitución, y reclamando además la falta de otras oportunidades de vida para estas personas.

En marzo de 1998 finalmente fue formulado el Código de Convivencia Urbana, según el cual debería intervenir un fiscal antes de que la policía labrara un acta contravencional o efectuara un arresto. Sin embargo, algunas "asociaciones de vecinos" habitantes de la calle Godoy Cruz y sus aledañas en el barrio de Palermo- se manifestaron en contra de dicho código y reclamaron el establecimiento de una zona roja en un lugar apartado de la ciudad. Las disputas entre estos grupos vecinales y aquellos de travestis se hicieron muy frecuentes en este período. La presión de 
algunos sectores conservadores ${ }^{4}$ fomentó la modificación del código en julio del mismo año, mediante la formulación del artículo $n^{\circ} 71^{5}$ : la oferta de sexo en la vía pública no estaría prohibida, pero sí los ruidos molestos y la alteración del orden público. En marzo de 1999, por decreto del presidente Menem se restablecieron los edictos, con medidas pre-delictuales que permitían las detenciones sin orden judicial, entre otras cosas por ofrecimiento o incitación al acto sexual cuando indujere la perturbación de la tranquilidad. Seguidamente la Legislatura porteña prohibió completamente el comercio sexual, sancionándolo con multas y/o trabajo comunitario. Estas medidas fueron repudiadas por las travestis, puesto que otorgaban nuevamente libertad a la policía para perseguirlas e imponerles el pago de coimas. Durante ese mismo mes protestaron colectivamente en el Obelisco, exigiendo que se levantara la prohibición de ofertar sexo en la vía pública. En ocasión de la visita del príncipe del Reino Unido, se manifestaron frente a la embajada británica pidiendo asilo político para sesenta y siete travestis, pero, antes de poder entregar el petitorio por escrito, fueron reprimidas por la policía. ${ }^{6}$

El siguiente hito en la sucesión de conflictos relativos al Código Contravencional fue el 16 de julio de 2004, mientras se debatían las reformas sobre el uso de los espacios públicos impulsadas por uno de los partidos políticos de derecha: la protesta de distintos grupos frente a la Legislatura derivó en serios

${ }^{4}$ Vinculados a partidos políticos de derecha y sectores reaccionarios de la Iglesia, que reclamaban una mayor represión y control de los espacios públicos con la reinstauración de las normativas del período militar.

${ }^{5}$ Artículo $N^{\circ}$ 71: "Alteración a la tranquilidad pública. Causar alteraciones a la tranquilidad pública frente a viviendas, establecimientos educativos o templos, o en su proximidad, con motivo u ocasión del ejercicio de la prostitución y como resultado de su concentración, de ruidos o de perturbación del tránsito de personas o vehículos, o con hostigamiento o exhibiéndose en ropa interior o desnudo/a. Se dará intervención al Ministerio Público Fiscal cuando corresponda aplicar el artículo $19^{\circ}$ de la Ley 10" (Berkins y Fernández, 2005:46).

${ }^{6}$ Ver en: http://www.youtube.com/watch?v=qgRWN04hkwQ. 
incidentes a partir de los cuales fueron detenidas quince personas, liberadas recién en septiembre de 2005. Estas reformas competían no sólo a las travestis sino a mujeres también en situación de prostitución y vendedores ambulantes. Finalmente en dicho año empezó a regir el nuevo código, que autorizaba la prostitución en espacios públicos sólo si era ejercida a más de 200 metros de distancia de viviendas, escuelas y templos. En consecuencia, "las travestis de Godoy Cruz" fueron mudadas al Rosedal", convertido desde ese momento en zona roja.

Tres años después, en julio de 2007, el subsecretario de Áreas Protegidas, dependiente del Ministerio de Medio Ambiente porteño de Jorge Telerman, dispuso una resolución que declaraba el Rosedal y sus alrededores "espacio no autorizado para la oferta o demanda de servicios sexuales". Dicho funcionario, hasta el año anterior había sido director del parque en cuestión, cargo a través del cual había acordado normas de convivencia con las travestis y prometido desarrollar actividades de inclusión social como talleres de capacitación en oficios. Sin embargo, en su nuevo puesto decidió ampararse en una resolución de la Defensoría del Pueblo que, ante una nueva denuncia de un grupo de vecinos molestos por las travestis, ordenó a la Comuna "disponer lo necesario en materia administrativa y, de resultar necesario, en el ámbito judicial" para "preservar" el Rosedal. En dicha denuncia se argumentaba que las travestis habían "tomado" el Rosedal, que los "vecinos" y sus "familias" ya no podían visitarlo por la masiva presencia de ellas y sus clientes, además del deterioro ambiental que generaban al arrojar preservativos usados al pasto. Ante esta medida, las organizaciones de travestis convocaron a una movilización en Plaza de Mayo, frente a la Jefatura de Gobierno, con la consigna "Si nos echan del Rosedal, nos venimos a la Plaza". Durante la concentración fue leída una carta, mientras algunas activistas se reunían con el ministro de Medio Ambiente del Gobierno de la Ciudad y la jefa de Gabinete del mismo. En el

7 Parque de grandes dimensiones en el barrio de Palermo, relativamente alejado de las zonas residenciales. 
transcurso de la reunión, el ministro se disculpó en nombre del Gobierno de la Ciudad, anulando la medida tomada por su subsecretario y convocando a las organizaciones a reunirse con miembros de distintos ministerios para trabajar en políticas de inclusión social para las travestis. Asimismo, días después se organizó una "mesa de diálogo" integrada por las organizaciones de travestis y de otras trabajadoras sexuales, y asociaciones barriales, donde una ONG internacional actuó como mediadora. Finalmente, se resolvió trasladar la zona roja a uno de los laterales de la Plazoleta Florencio Sánchez del Parque Tres de Febrero, entre las inmediaciones del Lago de Regatas y el Lawn Tennis Club. Este nuevo espacio estaba aún más alejado de las zonas residenciales, $y$ en ese momento fue equipado con baños químicos, cestos bacteriológicos, luminarias y lomos de burro. Se acordó acotar el horario de trabajo entre las 22 y las 6 , y se prometió una limpieza diaria del lugar y capacitaciones semanales en salud sexual y cuidado del medio ambiente para las travestis.

Las disputas sobre la regulación del espacio público iniciadas a fines de la década de 1990 se resolvieron, para el caso de Palermo, con una mayor intervención gubernamental en la gestión del espacio, los horarios y las condiciones del ejercicio de la prostitución, principalmente travesti. El argumento del escándalo en la vía pública fue articulado en este debate con el de preservación ambiental, y fundamentalmente moral, del Rosedal para los vecinos de Palermo; y se estableció formalmente como zona roja, a pesar de la postura abolicionista de Argentina con respecto a la prostitución (Cutuli, 2012).

En esta línea, autores/as como Sabsay y Boy elaboraron el conflicto profundizando en las tensiones entre ciudadanía, espacio urbano y moralidades. La primera analizó detalladamente las disputas -protagonizadas por travestis y mujeres en situación de prostitución- en torno a la derogación de los Edictos Policiales en la Ciudad de Buenos Aires, aportando el concepto de "fronteras sexuales" para pensar la conformación de sujetos políticos en la lucha por el espacio urbano y la ciudadanía (Sabsay, 2011). Por su parte, Boy desplegó las diferentes argumentaciones que pusieron 
en debate cuál era el proyecto de ciudad que debía promoverse desde las políticas públicas -quién merecía vivir en la ciudad y quién no- argumentando cómo el conflicto urbano devino un problema político (Boy, 2015). Siguiendo estas articulaciones entre moralidades y política, procuro en los siguientes apartados explorar otros dos momentos del proceso de politización de las travestis, para situar la conformación de imágenes morales que condensaron campos de disputa cambiantes.

\section{El trabajo digno para las travestis y sus correlatos moralizantes}

El año 2003 inauguró en Argentina un marcado cambio de paradigma en la gestión estatal del problema de la desocupación. Los programas de empleo a partir de ese año comenzaron a alentar la generación de emprendimientos productivos, desestimando el modelo de los planes sociales "asistencialistas" característicos de la década de 1990 (Manzano, 2013). La creación de cooperativas de trabajo, no sólo a partir de experiencias de recuperación de empresas quebradas, sino también como forma de inclusión social para sujetos con trayectorias laborales fragmentarias e informales, se constituyó como uno de los dispositivos privilegiados para la gestión del empleo de los sectores populares. Las categorías de trabajo genuino y trabajo digno condensaron el potencial para encauzar las demandas de diferentes colectivos en tiempos de crisis, así como para expresar las conquistas de la última década (Fernández Álvarez, 2006; Manzano, 2013). Para el caso de algunas agrupaciones de travestis, este cambio de paradigma representó la posibilidad de disputar la inserción en las nuevas políticas enfocadas hacia la producción, movilizando la conceptualización de la prostitución como indigna y reforzando la idea del trabajo como un ordenador moral, garante de dignidad. En esta construcción se basó la demanda por mejores condiciones de vida para estas personas, desplazando los objetivos activistas desde el cese de la represión policial y la derogación de los Códigos de Faltas, hacia el pedido de políticas públicas que las incluyeran a través del trabajo. 
Por lo tanto, el escenario de disputa conformado en torno a la lucha antirepresiva fue reconfigurado durante este período, en el que se pasó de discutir las condiciones en las que la prostitución sería ejercida -cómo se regularía el uso del espacio público y qué atribuciones tendría la policía; a categorizar, desde un paradigma abolicionista, a la prostitución como un destino siniestro $e$ inevitable para las travestis, construyéndolas como una población sufriente-. La Asociación de Lucha por la Identidad Travesti y Transexual (ALITT) protagonizó el activismo en esta etapa, generando una serie de iniciativas que incluyeron el litigio estratégico por la obtención de su personería jurídica ${ }^{8}$ y la confección de censos e informes cualitativos, generando pruebas cuantificables sobre la situación de fragilidad y precariedad extrema en la que se encontraba la comunidad en cuestión. Tanto las estadísticas como el relato explicativo del acaecer de la vida travesti generaron un conocimiento no sólo coherente e innovador - ya que no existían registros cuantitativos previos - sino sumamente potente, al constituirse en puntos de partida indiscutibles para cualquier estudio social, iniciativa activista o política pública en torno al travestismo. Estos indicadores abonaron a la idea de que la prostitución no era una elección, sino una situación: el único medio de vida para las travestis ante la falta de otras oportunidades laborales. ${ }^{9}$

8 Los casi cinco años de litigio por la personería jurídica de ALITT, en los que se disputaba si una asociación de travestis contribuiría o no al "bien común", contribuyeron además a visibilizar la problemática, convocando a diferentes académicas/os y referentes sociales de renombre a presentar escritos en calidad de Amicus Curiae. Finalmente, el caso llegó hasta la Corte Suprema de Justicia, la cual se expidió favorablemente en 2006. El expediente completo de la causa fue publicado como libro al año siguiente, bajo el título Políticas de reconocimiento, y en un segundo tomo se editaron los cinco Amicus Curiae que, no obstante, no habían sido aceptados como tales por la Corte.

9 Como señala Virginia Manzano, los registros censales llevados a cabo por integrantes de organizaciones sociales se constituyeron en las pruebas para legitimar y argumentar demandas, abriendo espacios de negociación con diferentes instancias estatales (Manzano, 2008 y 2013). En el caso de las travestis, además, las estadísticas le dieron cuerpo a la delimitación y la construcción de 
La primera iniciativa en ese sentido fue la gestión de cinco máquinas de coser ante el Ministerio de Desarrollo Social de Nación, a través del Programa "Ayudas Urgentes", en el año 2005. No obstante, sin tener un lugar donde instalar el taller, las máquinas quedaron guardadas por años en un depósito. Tras un largo proceso de demandas y gestiones, en 2008 la organización consiguió formar una cooperativa de trabajo textil en el partido bonaerense de Avellaneda, empleando a más de cuarenta personas, en su mayoría travestis, pero también a algunas mujeres $y$ varones. El emprendimiento, primero en el mundo con estas características, recibió financiamiento del Ministerio de Trabajo, Empleo y Seguridad Social y del Instituto Nacional de Asociativismo y Economía Social (MTESS e INAES, respectivamente) para solventar cursos de capacitación y equipamiento, y comprar y refaccionar la sede donde funciona. Durante los primeros cuatro años, las asociadas percibieron un subsidio mensual como apoyo para asistir a las clases, otorgado por el Ministerio de Trabajo, así como cajas de alimentos no perecederos por parte del Ministerio de Desarrollo.

En un proceso de construcción conjunta, agentes estatales y activistas travestis fueron modelando y disputando demandas y formas de intervención estatal, instituyendo la formación de cooperativas como un dispositivo de salida de la prostitución e inclusión social a través del trabajo. Así, las integrantes de la primera cooperativa incentivaron $e$ instruyeron a activistas de otras localidades en la creación de nuevos emprendimientos productivos, consiguiendo sumar una experiencia por año entre el 2008 y el 2012. Ante las demandas por alternativas laborales a la prostitución, la respuesta de los agentes estatales fue emplear todos los recursos necesarios para convertir a las travestis en trabajadoras dignas, a través de la creación de cooperativas - en tanto dispositivo privilegiado para la generación del empleo en sectores populares.

una población específica que previamente no era identificada como tal por el Estado. 
Autores como Corrigan y Sayer (2007) sostienen que el poder del Estado usualmente reside tanto en sus formas coercitivas como en las reguladoras, que definen ciertos tipos de sujetos $e$ identidades, negando otros. La implementación de este dispositivo trajo aparejados, de hecho, una serie de cambios con efectos "disciplinantes" en la vida cotidiana de las personas involucradas, como la obligatoriedad de capacitarse, presentar informes, cumplir horarios, normas y objetivos laborales. A través de sus políticas y agentes, se desplegó sobre este grupo de travestis todo un repertorio de instituciones, rutinas y reglas, construyéndolas como trabajadoras cooperativistas, indicando cuáles eran los límites de lo posible y lo aceptable. En este sentido, todos los emprendimientos generados respondían a oficios feminizados, como los de confección, peluquería y gastronomía.

En un contexto previo en que el trabajo se había constituido en la principal demanda de diversos sectores populares, diferentes políticas de recuperación del empleo instauraron a partir de 2003 al trabajo digno - y sus - como el "marco común" entre las iniciativas estatales y las demandas de las organizaciones sociales. En este sentido, Roseberry sugiere que

(...) las formas y los lenguajes de protesta o resistencia deben adoptar las formas y los lenguajes de la dominación para ser escuchados o registrados (...) en la medida en que un orden dominante establece tales procedimientos legítimos, en la medida en que establece no el consenso sino las formas prescritas para expresar tanto aceptación como descontento, ha establecido un marco discursivo común (Roseberry, 2007:130).

Las demandas de ALITT se incorporaron al "marco común" condensado en la idea de trabajo digno, en línea con los postulados abolicionistas que negaban a la prostitución como tal. Los libros editados desde ese espacio mostraban a través de sus estadísticas por qué las travestis conformaban una población en 
situación de vulnerabilidad. ${ }^{10}$ El proceso de institucionalización de las cooperativas integradas por travestis se dio en el marco de relaciones de hegemonía que ubicaron al trabajo digno dentro de los límites de lo que era posible demandar, así como a la cooperativa en el horizonte de lo que se podía conseguir en este contexto. Simultánea y contradictoriamente se disputó la instauración de un dispositivo que evidentemente proponía mejorar las condiciones de vida de estas personas, en un doble proceso de subjetivación y sujeción.

Roseberry advierte, no obstante, que la categoría de hegemonía debe iluminar más la lucha que el consenso, ya que ese marco común resulta ser siempre inacabado y disputado. Sin detenerme en este punto $^{11}$, me interesa aquí enfatizar que la formación de cooperativas, en tanto dispositivo de salida de la prostitución desplegado para convertir a las travestis en trabajadoras dignas, tuvo como correlato la sedimentación de una imagen moral muy potente que podría llamarse "la travesti permitida". Esta imagen parafrasea las formulaciones de Silvia Rivera Cusicanqui y Charles Hale sobre "el indio permitido",

${ }^{10}$ En 2013, tras la sanción de la Ley de Identidad de Género y en el marco de los vínculos previos establecidos con las activistas, la Secretaría de Empleo del Ministerio de Trabajo, Empleo y Seguridad Social de la Nación creó la Línea de Inclusión Laboral para personas Travestis, Transexuales y Transgéneros (Resolución 331/2013), extendiendo como población beneficiaria del Seguro de Capacitación y Empleo a personas cuya identidad de género no coincidía con el sexo asignado al nacer. Las personas trans fueron consideradas como una población vulnerable, junto con personas víctimas de explotación sexual o en situación vulnerabilidad vinculada a la prostitución y a mujeres víctimas de violencia doméstica. Este Seguro procuraba fomentar la búsqueda de un empleo de tres maneras: la generación de un microemprendimiento, la oferta de puestos de trabajo por parte de empleadores conectados a las oficinas de empleo, o a través de contratos mixtos entre organismos estatales o entes privados por los cuales el MTEySS se hacía cargo de una parte del salario por un período de tiempo estipulado. El Seguro brindaba además un incentivo extra para incentivar la terminalidad educativa y la formación continua.

${ }^{11}$ Para un análisis de las formas en que las travestis procesaron y encarnaron el "trabajo digno" ver Cutuli, 2015, capítulo 4: "La costurerita que dio el buen paso". 
figura que condensa las tensiones del multiculturalismo neoliberal en Latinoamérica:

\begin{abstract}
El Banco Mundial promueve los derechos culturales, y a la vez, emite el aviso de que no todas las formas de pluralidad cultural merecen ser aprobadas. Hacen una distinción resonante entre la "etnicidad buena", que fomenta el capital social, y la "etnicidad disfuncional", la que genera conflicto (...) El "indio permitido" es una categoría sociopolítica; no se refiere a una persona en particular. Retomamos la frase de la socióloga boliviana Silvia Rivera Cusicanqui, quien, durante un taller sobre derechos culturales y democratización en América Latina, la emitió en un momento de frustración y desesperación. Tenemos que encontrar, dijo Rivera, un método para describir cómo los gobiernos utilizan los derechos culturales para dividir y neutralizar a los movimientos indígenas. (...) Uso el término, precisamente para hacer referencia a los efectos agregados de estas políticas que, independiente de las sensibilidades $e$ intenciones de los individuos que las implementan, han servido para perpetuar la subordinación que al término expresa (Hale, 2004:4).
\end{abstract}

Más allá del indiscutible impacto concreto en mejorar las condiciones de vida de las personas involucradas, o de las resistencias que ellas mismas desplegaron en el cotidiano para resistir los aspectos más disciplinantes; puede pensarse que la empresa moralizante del "trabajo digno para las travestis" operó, en un contexto crecientemente represivo, como constituyente de su contracara: la narcotravesti. A diferencia de aquéllas sufrientes que se prostituyen para sobrevivir pero se esfuerzan por dejar de hacerlo; la figura de la narcotravesti se construyó demonizando a las migrantes latinoamericanas, imputadas de valerse de la prostitución como medio para comercializar estupefacientes. Exploraremos a continuación la trama de esta imagen moral. 


\section{Crónicas de la travestofobia xenófoba}

En agosto de 2013 se inauguró un nuevo ciclo de disputas en torno a la localización de una zona roja, esta vez en la ciudad de La Plata. Durante ese mes, alrededor de cincuenta travestis fueron detenidas y encarceladas como respuesta a una serie de llamados anónimos a la policía, denunciando disturbios y venta de drogas en la vía pública durante la madrugada. Nuevamente el antagonismo entre las travestis y "los vecinos" de un barrio residencial de clase media justificaba las iniciativas del gobierno local para mover la zona roja hacia un lugar más apartado.

En el marco de dichas disputas, en abril de 2014 una travesti de nacionalidad peruana fue detenida allí con 1,6 gramos de cocaína. Tras dos años de proceso judicial, el Tribunal Oral en lo Criminal I de dicha ciudad la condenó a cinco años y tres meses de prisión, encontrándola culpable de comercializar estupefacientes y considerando una serie de agravantes propuestos por el fiscal de la causa. Entre ellos, se ponderó el grado de toxicidad de la sustancia que vendía, su comercio en la vía pública, el perjuicio para "los vecinos" del lugar, la nocturnidad de estas acciones y el ejercicio de la prostitución como supuesta fachada para encubrir la venta de drogas. El principal agravante fue, no obstante, "su condición de extranjera". El juez no sólo ordenó su detención inmediata, sino que ordenó al nuevo intendente de La Plata (PRO-Cambiemos) a que resolviera "el problema de la zona roja" y las molestias ocasionadas a los vecinos, al mismo tiempo que solicitó a la Dirección Nacional de Migraciones informar bajo qué circunstancias legales se encontraban "los ciudadanos extranjeros que vienen a Argentina a ofrecer servicios como travestis".

Las organizaciones locales con trabajo en diversidad sexual, así como el Consulado de Perú, repudiaron los fundamentos xenófobos que funcionaron como agravantes de la pena. En todo momento de la causa judicial fue tratada como un varón, o en su 
defecto como una "persona travestida"12 - al igual que los medios gráficos platenses que cubrieron el proceso. Fueron éstos quienes instalaron la categoría de "narcotravestis" para dar cuenta de la presencia de estas travestis de países de la región, asociada al comercio callejero de estupefacientes en la llamada zona roja platense.

Según los registros del Sistema Penitenciario Federal y del Servicio Penitenciario Bonaerense, la mayoría de las travestis privadas de su libertad en 2016 fueron detenidas por haber infringido la ley de drogas, específicamente por venta al menudeo. ${ }^{13}$ En particular, en la Provincia de Buenos Aires las presas son predominantemente extranjeras, provenientes de Perú, Ecuador, Colombia y Paraguay. ${ }^{14}$ Un informe reciente del Centro de Estudios Legales y Sociales indicó:

Tomando como referencia comparativa la nacionalidad de las detenidas, la organización OTRANS realizó un seguimiento de causas de personas detenidas en la vía

${ }^{12}$ La travesti detenida no había realizado el cambio registral, ya que la Dirección Nacional de Migraciones pone como condición la residencia permanente y el tener documento argentino para poder solicitar el cambio de nombre. El citado informe del CELS denuncia: "En lo fáctico pueden pasar varios años hasta tener el documento definitivo con la identidad de género autopercibida. Esto constituye una violación a los derechos humanos de las personas trans y travestis migrantes por parte del Estado argentino al no reconocer y respetar su identidad de género autopercibida desde el primer trámite de regularización migratoria, lo que tiene un poderoso efecto excluyente en múltiples dimensiones de la vida de estas personas" (CELS, 2016:23).

${ }^{13}$ Ver informe presentado ante la CEDAW por el CELS en octubre de 2016: el $91 \%$ de las mujeres trans y travestis bajo custodia del Servicio Penitenciario Bonaerense (SPB) se encuentran privadas de la libertad por infracción a la ley de drogas. En el caso de las mujeres trans y travestis migrantes privadas de libertad en el SPB, el $100 \%$ está presa por estupefacientes. No existe otro grupo poblacional que esté preso en su totalidad bajo la misma calificación. Esto da cuenta del uso excluyente de la ley 23.737 como método de criminalización" (CELS, 2016: 7).

${ }^{14}$ Ver cifras publicadas en:

https://www.pagina12.com.ar/diario/suplementos/soy/1-4765-2016-09-23.html 
pública por infracción a la ley de estupefacientes y observó que mientras sólo el 3\% de la población total privada de libertad en el Sistema Penitenciario Bonaerense es extranjera, la población de mujeres trans y travestis extranjeras representa el $85 \%$ de la población total de mujeres trans y travestis privadas de su libertad. Aquí se evidencia el impacto de la doble discriminación. Todas las detenidas por estupefacientes en la provincia de Buenos Aires de nacionalidad extranjera fueron detenidas en La Plata, en la zona de Plaza Matheu, la zona roja (CELS, 2016:22).

En un contexto crecientemente represivo, la migración regional pasó de pensarse como un derecho a un problema de seguridad que atenta contra el orden público ${ }^{15}$ (Canelo, 2016); engarzándose con procesos de estigmatización previos que construyeron y movilizaron estereotipos en torno a la identificación de esos migrantes con el narcotráfico y otros delitos. Para el caso de las travestis migrantes, derogados los Edictos policiales y los códigos de faltas persecutorios, en este nuevo escenario la Ley de Drogas ( $n^{\circ}$ 23.737) resultó ser el dispositivo punitivo utilizado para criminalizarlas.

Las condiciones de detención y traslado fueron denunciadas por la Defensoría del Pueblo de la Provincia de Buenos Aires y las organizaciones de diversidad sexual platenses, no sólo por incumplir la Ley de Identidad de Género (26.743), sino fundamentalmente porque las requisas en la vía pública eran realizadas por personal policial masculino, utilizando la modalidad coercitiva de desnudez forzosa. ${ }^{16} \mathrm{El}$ activismo local se dio a la estrategia de presentar un Habeas Corpus ante cada detención

\footnotetext{
${ }^{15}$ Recordemos que la Dirección Nacional de Migraciones comunicó el 19 de agosto de 2016 la firma de un acuerdo para crear un centro de retención de personas infractoras de la Ley Nacional de Migraciones 25.871, en el marco de la mencionada nueva lectura sobre la migración. Esto fue repudiado ampliamente por organizaciones de migrantes y organismos de Derechos Humanos.

${ }^{16}$ Ver informe del Observatorio de Género de la Defensoría del Pueblo de la Provincia de Buenos Aires de 2014 denunciando esta situación.
} 
para objetar estos procedimientos, y en particular para visibilizar la persecución de las travestis migrantes por parte del personal de la Comisaría $9^{\circ}$ de La Plata. Uno de los Habeas Corpus presentado en favor de cuatro travestis detenidas en la zona roja, acusadas de comercializar estupefacientes, se resolvió en la que se llamó "doctrina Zambrano" (apellido de una de las migrantes apresadas), anulando el procedimiento de detención por ser considerado "vejatorio en grado sumo". ${ }^{17}$ En este fallo, la justicia calificó que el mismo "no se ajustó a las formalidades y exigencias legales, por violentar gravemente las garantías constitucionales instituidas en favor de las personas en situación de detención". Sentando jurisprudencia, se determinó entonces que los procedimientos de requisas corporales deberían realizarse por personal debidamente capacitado y exclusivamente por personas del mismo género, garantizando además la privacidad e integridad $\mathrm{del} / \mathrm{a}$ detenido/a.

Pero como en todo proceso de disputa, las fuerzas de seguridad también desplegaron sus estrategias y recursos creativos, apropiándose de los nuevos derechos que ponían límites a su accionar. Ante la impugnación del procedimiento previo por no haber sido realizado por "personas del mismo género" que las requisadas, el comisario platense convocó a Malena, la primera oficial de policía trans de la provincia de Buenos Aires, para que efectuara las requisas en la zona roja. Trasladada desde el interior de la provincia, participó junto al personal de calle de la Comisaría $9^{\circ}$ del siguiente operativo. Vestida de uniforme, con el pelo prolijamente recogido, aros de perlas y maquillaje, relató el procedimiento para el diario El Día de La Plata. Tras realizar tareas de observación y dar con personas que habían comprado estupefacientes, procedieron a la detención y a la requisa:

Respecto del biombo, eso se hizo por cuestiones de seguridad, porque no es la primera vez que califican un

\footnotetext{
${ }^{17} \mathrm{http}: / /$ www.tiempoar.com.ar/articulo/view/60451/freno-judicial-a-los-abusospoliciales-a-mujeres-trans
} 
procedimiento como vejatorio, respecto a cómo se hace la requisa en la zona. En realidad, muchas veces $-y$ lo digo desde mi lugar- mucha gente, en el afán de querer zafar o de querer justificarse, toma el hecho de la sexualidad, como que no hay otra salida. Y justifican desde ese lado el hecho de vender drogas, la prostitución o lo que fuere... "ah, no, me requisaron porque soy una chica trans, o porque soy una travesti". No, la sociedad no dice que por el hecho de ser travesti hay que prostituirse o vender estupefacientes. Hay otro estilo de vida y hay muchas salidas, no es necesario llegar a eso. ${ }^{18}$

La presencia de esta oficial y el uso del biombo garantizaron que el nuevo procedimiento no pudiera ser objetado. La entrevista audiovisual prosiguió con preguntas personales, en las que detalla su vida cotidiana y sus aspiraciones. La ley de Identidad de Género y los estándares de Derechos Humanos conquistados durante la pasada década crearon las condiciones de posibilidad para que Malena, entre otras travestis, tuviera una alternativa laboral al ejercicio de la prostitución. Convertida en "la travesti permitida" de la policía provincial, su figura funciona del modo que alertaban Hale y Cusicanqui: estableciendo fronteras morales entre "buenas" y "malas" travestis, demonizando a las migrantes y abriendo intersticios para avanzar por sobre los derechos adquiridos.

\section{De avances y retrocesos, apropiaciones y reelaboraciones}

En este artículo nos detuvimos en tres momentos significativos del proceso de politización de las travestis para explorar la conformación de imágenes morales que dan cuenta de reconfiguraciones de los campos de fuerza. A través de ellos es posible proponer algunas reflexiones sobre los escenarios locales cambiantes.

18 "Ser travesti no es excusa para el delito". Entrevista audiovisual del Diario El Día de La Plata. 15/10/16. Ver en: http://www.eldia.com/policiales/cayo-presuntanarcotravesti-en-la-zona-roja-172637 
Una mirada transversal permite sugerir que en contextos crecientemente represivos las disputas por el espacio público se agudizan, reeditándose los guiones del conflicto y movilizando construcciones morales sobre prácticas e identidades. Los debates por la relocalización de la zona roja de Palermo se replican en La Plata una década después con los mismos antagonistas: las travestis -construidas como un "otro" amenazante- versus los vecinos, quienes detentan la legitimidad de conservar y usar el espacio público. Pero si hasta principios del nuevo milenio la disputa pasaba por quién podía ocupar el espacio público y para qué -siendo las travestis en ejercicio de la prostitución una alteridad radicalmente disruptiva que debía ser erradicada o por lo menos confinada- el período reciente presenta la complejidad de articular nuevos elementos en la imbricación del problema. Las peligrosas en La Plata ya no son todas las travestis, sino las migrantes de países de la región. La oferta de sexo en la vía pública pierde protagonismo en la definición del delito - e incluso aparece como un instrumento - en detrimento de la comercialización de estupefacientes. Derogados los Edictos policiales y los códigos contravencionales, el dispositivo legal para la represión es ahora la ley de drogas: la imagen de la narcotravesti peruana propone una nueva gestión de la diversidad cristalizada en la travestofobia xenófoba, reeditando pánicos morales que parecían superados.

¿Será que en serio creímos que éramos vanguardia? Preguntarnos por la idea de retroceso o giro conservador a través del derrotero político de las travestis -o de los Derechos Humanos en general- evidencia cómo los procesos resultan siempre inacabados. Seguimos a Pita y Tiscornia cuando señalan:

(...) no es de un día para el otro que los avances limitantes $y$ punitivos sobre derechos y libertades pueden resultar posibles. Esto es, las acciones y decisiones políticas concretas operan sobre ciertas condiciones de posibilidad que, a su vez están ancladas sobre una matriz de significación que se articula de manera casi orgánica con las burocracias locales. Si no hubiera aceitados resortes 
burocráticos, judiciales y administrativos que admitieran decisiones que resultan en avanzadas sobre derechos, libertades y garantías las mismas no serían posibles o bien enfrentarían mayores dificultades (Pita; Tiscornia, 2016:2).

Ciertamente, la vitalidad de los aparatos represivos y la fragilidad de las conquistas caracterizan este escenario. Pero de forma simultánea esos derechos adquiridos ponen límites, aunque sea parciales, y obligan al poder punitivo a repensar argumentos y estrategias. Si en trabajos anteriores analicé como las travestis se habían apropiado de la categoría de escándalo -inspirada en la figura contravencional de los Edictos $2^{\circ} \mathrm{H} \mathrm{y} \mathrm{F} \mathrm{-} \mathrm{para} \mathrm{resignificarla}$ y calificar modos propios de hacer, de ser y de estar (Cutuli, 2012 y 2015); el recrudecimiento conservador habilita a las fuerzas de seguridad a apropiarse de las posibilidades abiertas con los nuevos derechos, para reconvertir y agudizar sus prácticas persecutorias.

El contrapunto entre la "travesti permitida" y la "narcotravesti" permite no sólo desplegar dos imágenes morales en tensión, sino también dar cuenta de procesos inacabados, contradictorios. Derechos de avanzada, como la ley de Identidad de Género o la formación de cooperativas protegidas, se procesan en términos conservadores para normalizar a algunos/as $y$ profundizar la segregación y vulneración de otros/as. Resulta urgente, entonces, volver a mapear la disputa y recuperar sus temporalidades.

\section{Referencias bibliográficas}

BOY, Martín. Travestis y vecinos de la 'zona roja' de Palermo: distancias y cercanías en conflicto. Ciudad de Buenos Aires, 1998-2012. Sexualidad, Salud y Sociedad - Revista Latinoamericana (21) 2015, pp.175-196.

CANelo, Brenda. Acerca del centro de detención para migrantes. Del paradigma de los derechos al de la seguridad. Filo Debate, Facultad de Filosofía y Letras, Universidad De Buenos Aires, 2016 [http://investigacion.filo.uba.ar/sites/investigacion.filo.uba.ar/files/u6/FI LO\%20Debate Canelo.pdf - Consultado el 10 dec. 16]. 
ChEJTER, Silvia. El camino de Buenos Aires. Prostitución, ayer y hoy. Mora (15) 2009, pp.97-102.

CORRIGAN, Philip; SAYER, Derek. La formación del Estado inglés como revolución cultural. En: LAGOS, M; CALLA, P. (comp). Cuadernos de Futuro $\mathrm{n}^{\circ} 23$ Antropología del Estado: Dominación y prácticas contestatarias en América Latina. La Paz, INDH/PNUD, 2007.

CuTULI, María Soledad. Resisting, demanding, negotiating and being: the role of scandals in the everyday lives of Argentinean travestis. Jindal Global Law Review (4-1) 2012, pp.219-237.

CuTULi, María Soledad. Entre el escándalo y el trabajo digno. Etnografía de la trama social del activismo travesti en Buenos Aires. Tesis (Doctorado en Antropología), Universidad de Buenos Aires. 2015.

GENTILI, Rafael. Me va a tener que acompañar. Una visión crítica sobre los edictos policiales. Buenos Aires, CISALP, 1995.

HALE, Charles. El protagonismo indígena, las políticas estatales y el nuevo racismo en la época del 'indio permitido'. Ponencia presentada en la conferencia "Construyendo la paz: Guatemala desde un enfoque comparado". Misión de Verificación de las Naciones Unidas en Guatemala (MINUGUA), 27-29 de octubre, 2004 [Disponible en: http:/www.cedet.edu.ar/Archivos/Bibliotecas_Archivos/id40/hale\%20 protagonismo\%20indigena.pdf - consultado el 6 dec 2016].

MACKINNON, Catherine. Toward a feminist theory of the state. Cambridge, Harvard University Press, 1989.

PATEMAn, Carol. El contrato sexual. Barcelona, Anth-ropos, 1995.

PITA, María. Lo infinitamente pequeño del poder político. Policía y contravenciones en el ámbito de la Ciudad Autónoma de Buenos Aires. Tesis de Maestría. Universidad De Buenos Aires, 2004.

PITA, María; TISCORNIA, Sofía. Derechos Humanos y escenarios políticos. Filo Debate, Facultad de Filosofía y Letras, Universidad de Buenos Aires, 2016 [http://investigacion.filo.uba.ar/sites/investigacion.filo.uba.ar/files/u6/Fi lo\%20Debate Pita-Tiscornia.pdf - consultado el 10 dec. 2016].

SABSAY, Leticia. Fronteras sexuales. Espacio urbano, cuerpos y ciudadanía. Buenos Aires, Paidós, 2011. 
THOMPSON, Eduard Palmer. Tradición, revuelta y conciencia de clases. Madrid, Crítica, 1984.

\section{Fuentes consultadas}

AAVV. Políticas de inclusión y reconocimiento para el colectivo trans y travestis. Defensoría del Pueblo de la Provincia de Buenos Aires. Observatorio de Violencia de Género. La Plata, mayo de 2014 [http://www.defensorba.org.ar/ovg/pdfs/Politicas-de-inclusion-yreconocimiento-para-el-colectivo-trans-y-travestis.pdf - consultado el 24 set. 2016].

Ají De Pollo. Conversaciones Feministas. Políticas de Reconocimiento. Buenos Aires, Ed. Ají de Pollo / Gobal Fund for Women, 2008.

Ají de Pollo. Conversaciones Feministas. Políticas de Reconocimiento Tomo II. Buenos Aires: Ed. Ají de Pollo/Gobal Fund for Women, 2009.

BERKINS, Lohana; FERNÁNDEZ, Josefina. La gesta del nombre propio. Informe sobre la situación de la comunidad travesti en la Argentina. Buenos Aires, Ediciones de las Madres de Plaza de Mayo, 2005.

CENTRO de Estudios Legales y Sociales et al. Situación de los derechos humanos de las Travestis y Trans en la Argentina. Octubre de 2016. [http://bit.ly/2ef5BAN - consultado el 6 dec. 2016].

PAUlet Moreno y otros. Habeas corpus. Comercialización de estupefacientes. La Plata, 12/9/16.

RUCHANSKY, Emilio. Narcotrágico. Suplemento SOY, Página 12. 23/9/16. [https://www.pagina12.com.ar/diario/suplementos/soy/1-4765-201609-23.html - consultado el 24 set. 2016] 